\title{
SOME BASIC OBSERVATIONS ON HEAT TRANSFER AND EVAPORATION IN THE HORIZONTAL FLASH EVAPORATOR
}

\author{
$\because \quad$ NOAM LIOR \\ University of Pennsylvania, Philadelphia, Pa. 19104 (USA) \\ AND RALPH GREIF \\ University of California, Berkeley, Calif. 94720 (USA)
}

(Received September 30, 1979)

SUMMARY

This paper decribes a study of the heat, mass and momentum transp associated with vapor release in a horizontal stage of a flash evaporat A scaled-down, well-controlled flash evaporator, which also allows gc visual observation, has been designed, constructed and used in the exp4 ments. In particular, temperature profiles in the stage have been measured an accuracy of $\pm 0.02^{\circ} \mathrm{C}$ and better.

It has been determined that the subcritical flow in the flash stage consi of two principal regions: submerged sluice gate flow with the associal hydraulic jump overlayed by a backflow rolier, followed by open chan flow. The flashing of $\mathrm{NaCl}$ solutions was accompanied by strong foamis which has reduced the fractional non-equilibrium allowance by a factor two or three, without impairing the purity of the distillate.

\section{SYMBOLS}

$b \quad-$ width of stage

$C_{B} \quad-$ salt concentration of flashing liquid, ppm by weight

Fr - Froude number

$\mathrm{Fr}_{\mathrm{vc}} \quad$ - Froude number at the Vena Contracta

$h \quad$ - flashing liquid depth

$h_{c} \quad-$ critical depth of flow (for Fr $=1$ )

$h_{\mathrm{g}} \quad$ - vertical interstage gate opening

$h_{g d}$ - depth of liquid at the downstream side of the gate (measure 
$h_{i} \quad-$ liquid depth in inlet stage

$L \quad-$ length of stage

$L_{j} \quad$ - length of hydraulic jump as measured in flash stage

Lic - length of hydraulic jump in nonflashing water, as calcula Eq. (7)

$m_{B} \quad-$ mass flow rate of flashing liquid

$P_{v} \quad-$ vapor pressure

$q$ - total evaporative heat transfer rate in flash stage

$\bar{T}_{\text {in }} \quad$ - average liquid temperature at stage inlet

$\bar{T}_{0} \quad-$ average temperature of liquid at outlet from stage

$T_{v} \quad-$ vapor temperature

$V_{B} \quad$ - average velocity of flashing liquid

$x$ - distance along stage, measured from upstream edge of gate

$y \quad$ - distance above stage floor

Greek

$\beta \quad-$ fractional approach to equilibrium $=\frac{\bar{T}_{\dot{m} n}-\bar{T}_{0}}{\bar{T}_{i n}-T_{\nu}}$

$\triangle^{\prime} \quad$ - nonequilibrium, ${ }^{\circ} \mathrm{C}\left({ }^{\circ} \mathrm{F}\right)$

$\rho_{B} \quad-$ density of flashing liquid

$\triangle_{A M F}^{\prime}-$ "nonequilibrium allowance" calculated by the AMF cor [22], ${ }^{\circ} \mathrm{C}\left({ }^{\circ} \mathrm{F}\right)$

$\triangle ' B L H$ - "nonequilibrium allowance" calculated by the BLH col $[23],{ }^{\circ} \mathrm{C}\left({ }^{\circ} \mathrm{F}\right)$

$\triangle P_{v} \quad$ - interstage vapor pressure differential

$\triangle T_{F C} \quad$ - temperature flashdown in stage

\section{INTRODUCTION}

In most horizontal flash evaporators the superheated, free-surfa stream enters the flash stage through one aperture (usually a slui evaporates there, and leaves to the next stage through a second : The flashing brine evaporates both from the free surface and from The energy necessary for evaporation is supplied to these evaporati faces by heat transfer from the warmer bulk liquid. The heat transf anism is principally one of turbulent convection produced by the 1 the channel geometry (including interstage aperture). Thermodyni 
it is desired to bring all of the superheated brine close to the equilib state determined by the saturation conditions in the stage of minimal The flash evaporation process is one that involves coupled phenomen fluid dynamics, heat transfer, mass transfer and thermodynamics. A thor understanding of the whole problem is essential for any compreher attempt to improve the flash distillation process. The described prol is difficult to solve, either theoretically or experimentally. This fact is denced by the relatively small amount of information available, as well $a$ a fair amount of conflicting conclusions [1-12] .

The paper addresses itself to some of the questions related to the moc evaporation (surface or boiling), to bubble nucleation, to the flow, transfer and vapor release in the stage, and to the approach to equilibriu the flashing stream.

\section{II, THE EXPERIMENTAL APPARATUS}

A scaled-down, well-controlled flash evaporator was designed, constru and used in the experiments. The evaporator consists of an evaporating $\mathrm{s}$ $113 \mathrm{~cm}$ long, with an overhead full-length condenser and of a nonflas flow-straightening inlet stage, $73 \mathrm{~cm}$ long (Fig. 1). The stages have a angular cross-section, $7.8 \mathrm{~cm}$ wide, and are made of $70-30 \mathrm{Cu}-\mathrm{Ni}$ a The system incorporates large glass windows for good visual observat

The flow system (Fig. 2) is a closed loop with an independently co condenser. The flashing liquid is circulated by the main pump and is he to a constant (automatically controlled) temperature by the steam-he heat exchanger. It then enters the inlet stage through a system of $f$ straightening vanes and flashes in the flash stage before returning to the culation pump. The flashed-off vapor condenses in the condenser, and resulting distillate flows by gravity to a distillate collection and measuren system [13]. It is then pumped back to the suction side of the main culation pump to maintain constant brine concentration. The main , denser is cooled by city water.

Various instruments for the measurement of temperatures, presst flow rates and salinities were developed or adapted. In particular, a sir taneous multi-probe differential temperature measuring system (the " $t$ mistor comb" [14]), has been developed and utilized for the determina' of temperature profiles along a line vertical to the stage floor, in both liquid and vapor regions, to an accuracy of $\pm 0.02^{\circ} \mathrm{C}$ and better. Essenti: the thermistor comb consists of 68 bead thermistors, each $0.25 \mathrm{mn}$ diameter and bonded at the end of a $0.46 \mathrm{~mm}$ diameter, $20 \mathrm{~mm}$ long, hy dermic tube, the other end of which is mounted into a streamlined, w shaped holder (visible in Figs. 4,7 and 8). The thermistor comb can moved and positioned at any location along the stage. 


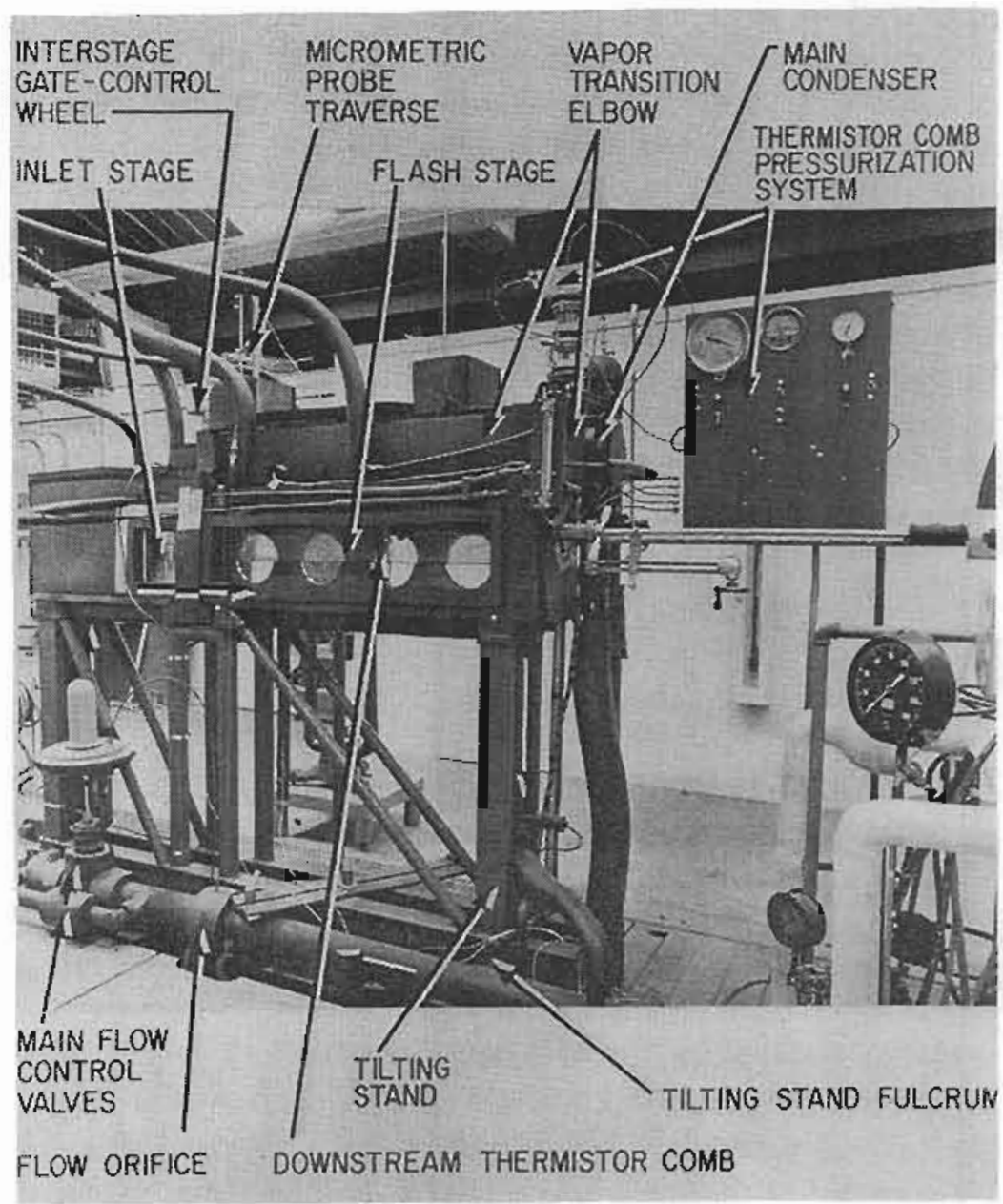

Fig. 1. The flash evaporator.

\section{THE EXPERIMENTS}

Most of the experiments were conducted with subcritical flow Froude number range of $0.1 \leqslant \mathrm{Fr}_{\text {stage }} \leqslant 0.2$, the flow depth being $11 \mathrm{~cm}$. A few experiments were performed with supercritical flow stage, having a Froude number of about 3 and a flow depth around The experiments were conducted at two temperatures, about $80^{\circ}$ $100^{\circ} \mathrm{C}$, and in the temperature flash-down range of $1^{\circ} \mathrm{C}$ to $3^{\circ} \mathrm{C}$. $\mathrm{Tw}$ ing liquids were used: fresh water (about $50 \mathrm{ppm}$ salt by weigh aqueous $\mathrm{NaCl}$ (reagent-grade) solution ( $41576 \mathrm{ppm} \mathrm{NaCl}$ by weight).

Data was acquired in the steady state, after the system has fully sta and photographs of the process were taken to provide better unders of the flash evaporation and fluid mechanics phenomena. Temperati files were obtained by recording simultaneously ten temperature-me 


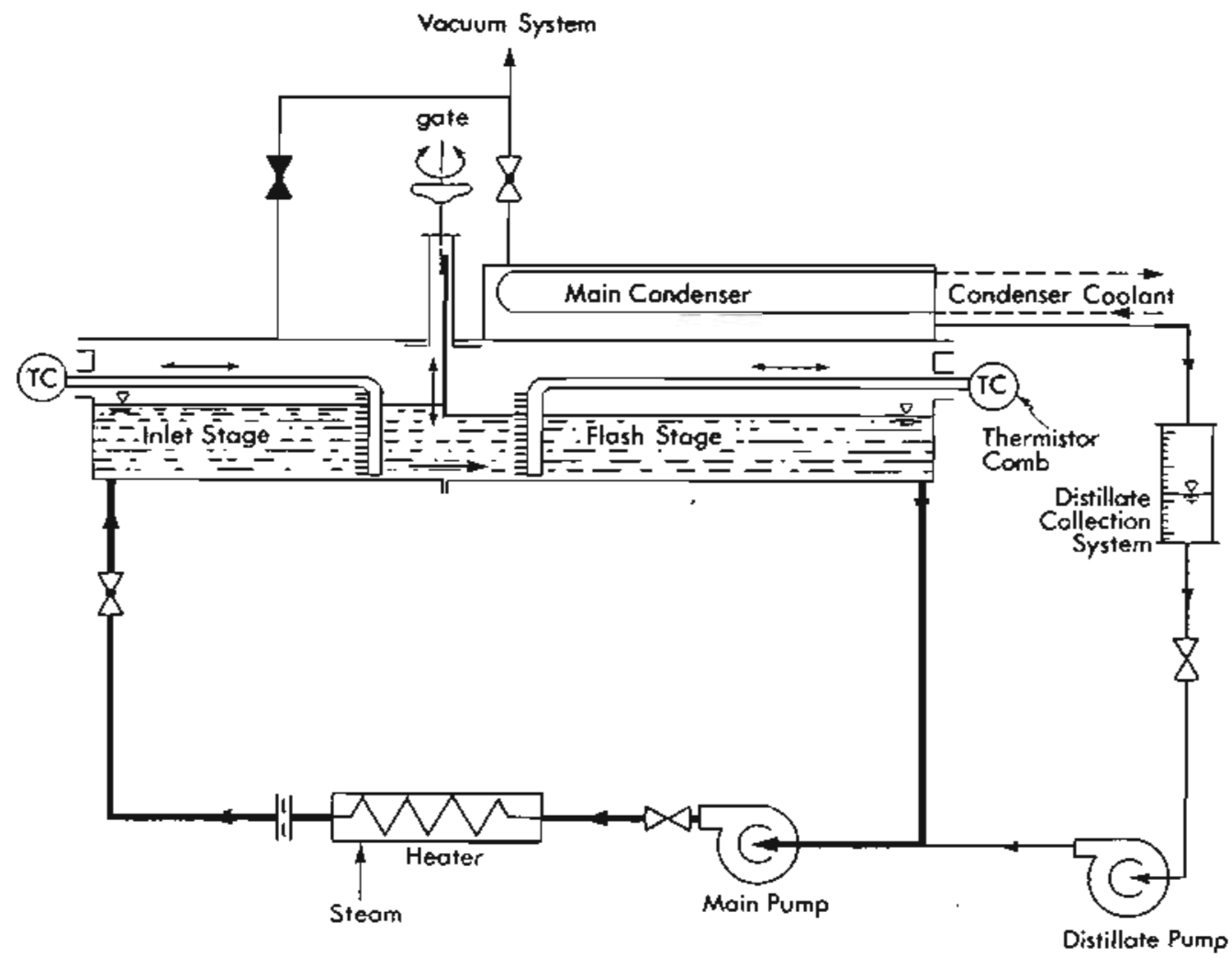

Fig. 2. Simplified flow diagram of the experimental system.

channels on the thermistor comb and repeating this for several posit: along the test stage and at least at one position in the inlet stage. Pro average temperatures were measured continuously at 12 different locati Other parameters measured included the distillate production rate, ve pressures and pressure differences, flow rates, and salinities of the flasl liquid and of the distillate.

IV. RESULTS AND ANALYSIS

\section{Summary of experimental results}

Some of the major experimental and derived results are listed in Tab and the meaning of the symbols is listed in the Nomenclature.

\section{Visual description}

The general flow pattern is depicted in the flow sketch (Fig. 3) and patterns for each run in the photographs (Figs. 4, 7 and 8). The first of the flow past the gate consists of a submerged hydraulic jump. back flow of its roller is distinctly two-phase. By following the motion of 
TABLE I

EXPERIMENTAL AND CALCULATED RESULTS

\begin{tabular}{|c|c|c|c|c|c|c|c|c|c|c|c|c|c|c|c|c|c|}
\hline 1 & 2 & 3 & 4 & 5 & 6 & 7 & 8 & 9 & 10 & 11 & 12 & 13 & 14 & 15 & 16 & 17 & 18 \\
\hline Run & $T_{v}$ & $P_{\nu}$ & $m_{B}$ & $\triangle \triangle T F_{C}$ & $\triangle^{\prime}$ & $\Delta_{A M F}^{\prime}$ & $\triangle_{B L H}^{\prime}$ & -6 & $q$ & $\Delta P_{v}$ & $\bar{h}_{i}$ & $h_{g}$ & $\overrightarrow{\vec{h}}$ & $\mathrm{Fr}$ & $\overline{L j}$ & $L_{t}$ & $C_{B}$ \\
\hline No. & ${ }^{\circ} \mathrm{C}$ & Bat & $\mathrm{kg} / \mathrm{s}$ & ${ }^{\circ} \mathrm{C}$ & ${ }^{\circ} \mathrm{C}$ & ${ }^{\circ} \mathrm{C}$ & ${ }^{\circ} \mathrm{C}$ & ${ }^{\circ} \mathrm{C}$ & $\mathrm{kW}$ & $\mathrm{kN} / \mathrm{m}^{2}$ & $\mathrm{~mm}$ & $\mathrm{~mm}$ & $\mathrm{~mm}$ & & $\mathrm{~mm}$ & $\mathrm{~mm}$ & ppm wt \\
\hline 1 & 96.81 & 0.9000 & 0.610 & 1.13 & 0.40 & 0.02 & 0.13 & 0.267 & 2.91 & 2.924 & 25 & 2.6 & 100 & 0.08 & 290 & 1185 & 47 \\
\hline 2 & 95,83 & 0.8761 & 0.611 & 1.72 & 0.40 & 0.01 & 0.11 & 0.183 & 4.43 & 3.712 & 25 & 2.1 & 85 & 0.11 & 310 & 1755 & 52 \\
\hline 3 & 94.83 & 0.8343 & 0.611 & 2.82 & 0.24 & 0.01 & 0.09 & 0.079 & 7.25 & 6.476 & 25 & 1.7 & 87 & 0.10 & 330 & 3268 & 47 \\
\hline 4 & 94.97 & 0.8457 & 0.611 & 2.38 & 0.40 & 0.00 & 0.04 & 0.138 & 6.13 & 6.397 & 25 & 1.7 & 8 & 3.65 & & & 47 \\
\hline 5 & 76.91 & 0.4196 & 1.256 & 1.91 & 0.40 & 0.03 & 0.21 & 0.189 & 10.06 & 1.935 & 30 & 12.4 & 110 & 0.15 & 340 & 643 & 47 \\
\hline 6 & 75.87 & 0.3998 & 1.270 & 2.47 & 0.35 & 0.03 & 0.17 & 0.123 & 14.10 & 3.245 & 35 & 9.0 & 107 & 0.15 & 350 & 1186 & 47 \\
\hline 7 & 76.14 & 0.4096 & 1.272 & 3.12 & 0.40 & 0.03 & 0.16 & 0.106 & 16.60 & 4.417 & 50 & 7.5 & 122 & 0.13 & 360 & 1414 & 47 \\
\hline 8 & 97.71 & 0.9423 & 1.259 & 1.04 & 0.54 & 0.02 & 0.15 & 0.305 & 5.50 & 2.499 & 32 & 9.5 & 100 & 0.17 & 470 & 735 & 48 \\
\hline 9 & 96.91 & 0.9183 & 1.259 & 1.98 & 0.41 & 0.02 & 0.13 & 0.168 & 10.51 & 4.371 & 30 & 7.6 & 120 & 0.13 & 490 & 811 & 48 \\
\hline 10 & 97.83 & 0.9291 & 1.258 & 2.54 & 0.24 & 0.02 & 0.11 & 0.087 & 13.44 & 6.551 & 30 & 6.0 & 115 & 0.14 & 500 & 1020 & 48 \\
\hline 11 & 97.19 & 0.9031 & 1.300 & 1.65 & 0.12 & 0.02 & 0.14 & 0.071 & 8.60 & 3.105 & 35 & 6.4 & 100 & 0.17 & 480 & 1610 & 41576 \\
\hline 12 & 97.37 & 0.9249 & 1.259 & 1.99 & 0.38 & 0.00 & 0.06 & 0.159 & 10.55 & 4.372 & 30 & 7,6 & 15 & 2.93 & & & 48 \\
\hline 13 & 97.14 & 0.9213 & 1.862 & 0.75 & 0.40 & 0.04 & 0.19 & 0.328 & 5.85 & 1.899 & 40 & 15.0 & 120 & 0.19 & 440 & 647 & 47 \\
\hline 14 & 96.12 & 0.8832 & 1.861 & 1.37 & 0.18 & 0.03 & 0.16 & 0.118 & 10.77 & 3.078 & 40 & 10.8 & 120 & 0.19 & 460 & 773 & 47 \\
\hline 15 & 96.88 & 0.9085 & 1.860 & 1.78 & 0.17 & 0.03 & 0.15 & 0.085 & 13.94 & 3.930 & 49 & 9.3 & 126 & 0.18 & 500 & 999 & 47 \\
\hline 16 & 97.20 & 0.9100 & 1.847 & 1.07 & 0.40 & 0.01 & 0.19 & 0.272 & 8.33 & 1.840 & 40 & 15.0 & 20 & 2.79 & & & 47 \\
\hline 17 & 77.96 & 0.4395 & 2.490 & 3 & Large & tempera & ature fiu & Jctuatio & & 1.451 & 45 & 25.4 & 110 & 0.29 & & & 47 \\
\hline 18 & 78.04 & 0.4401 & 2.505 & \} & & in vap & por spac & & & 2.543 & 48 & 20.5 & $13 I$ & 0.22 & & & 47 \\
\hline 19 & 99.12 & 0.9875 & 2.470 & 0.81 & 0.44 & 0.05 & 0.19 & 0.386 & 8.44 & 2.370 & 52 & 21.0 & 140 & 0.20 & 560 & 760 & 52 \\
\hline n & 9781 & $0 a, 18$ & 7.499 & 108 & ก 88 & $\cap \cap 4$ & 017 & $09.6 \%$ & 1147 & 2958 & $4 n$ & 180 & 130 & 0.23 & 580 & 833 & 47 \\
\hline
\end{tabular}


HORIZONTAL FLASH EVAPORATOR

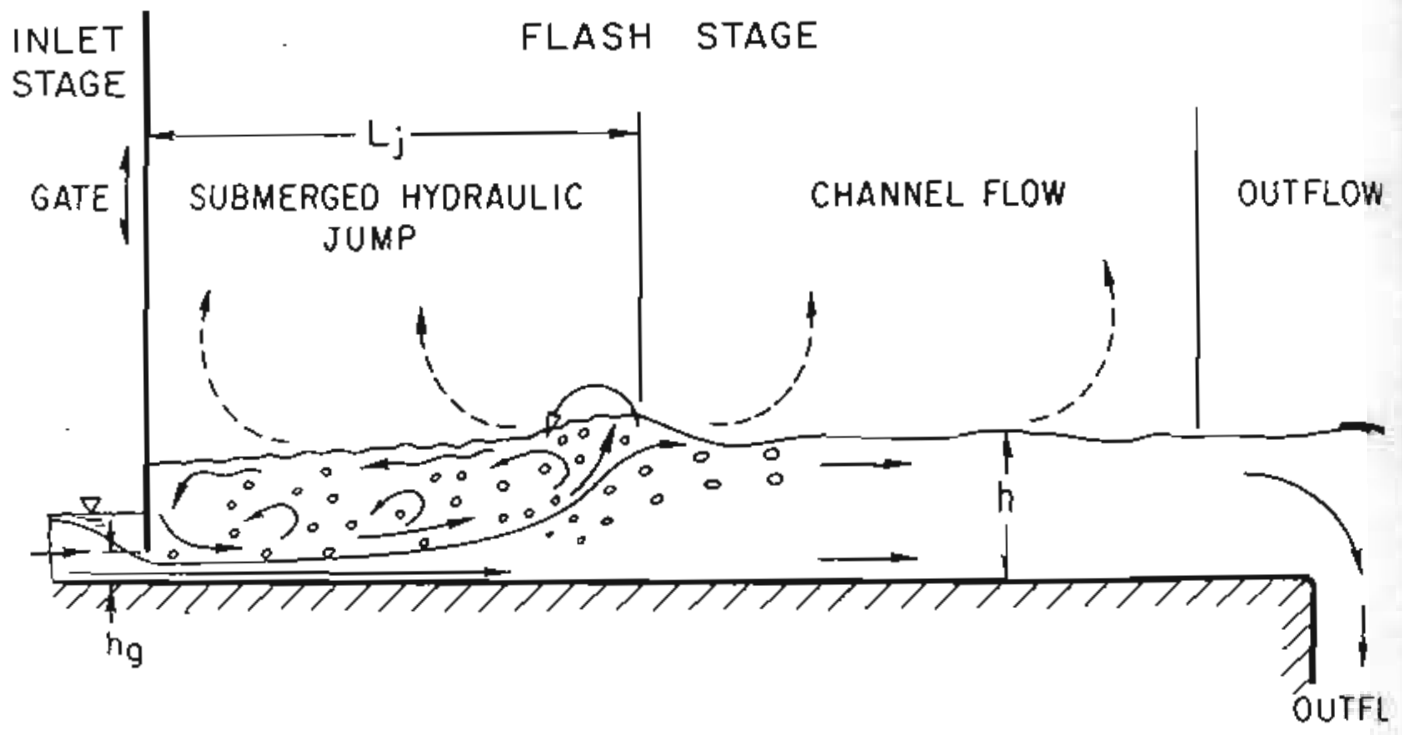

Fig. 3. Flow and flash patterns in the evaporator.
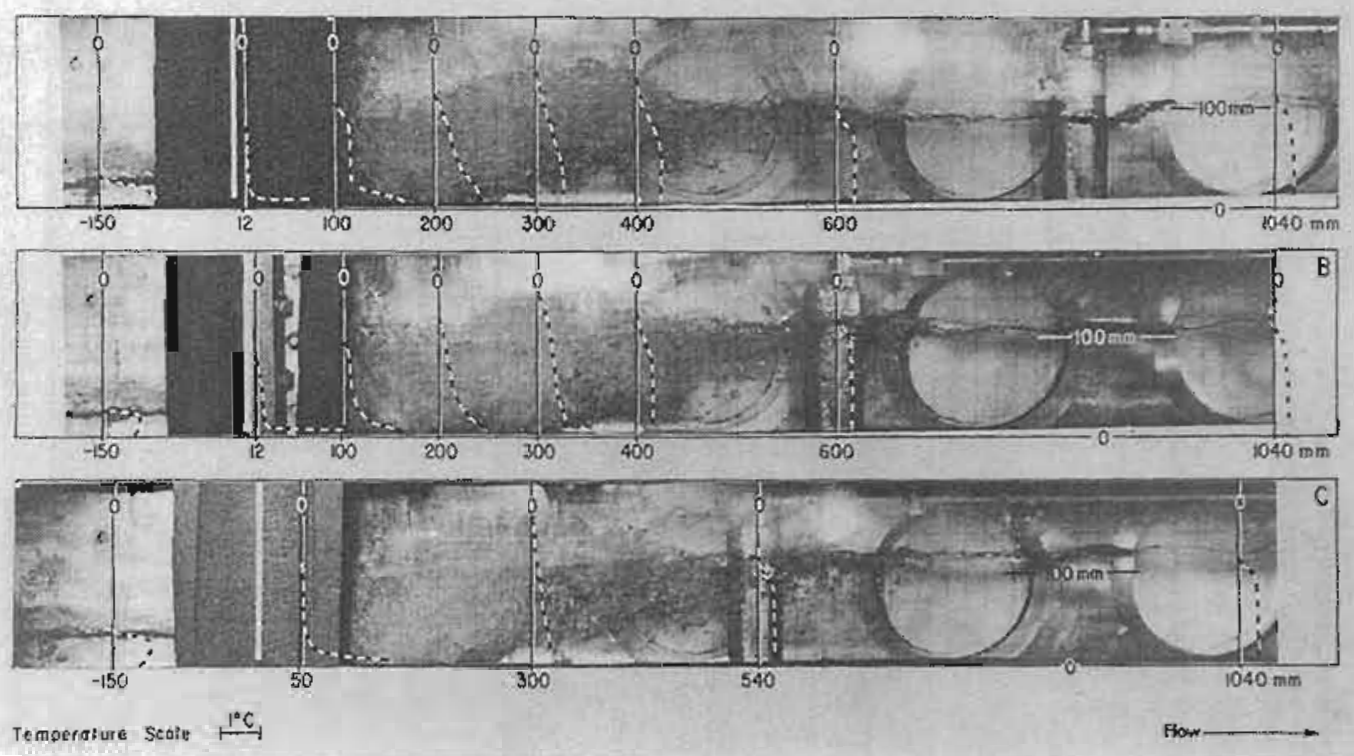

Fig. 4. Temperature distribution in the flash evaporator runs: A: No. 5; B: Ne C: No. 7 .

bubbles and of short silk strings bonded to the side wall of the thermis comb, it appears that the wall jet emerging from the sluice gate expa slowly away from gate, until it rather abruptly meets the free surface. this point, the free surface is uplifted and is vigorously wavy and bubl As the jet expands, it sheds eddies into the backflow roller. The roller regi including the roller-vapor interface, exhibits a high degree of turbuler 
A. Distance from Gate: $100 \mathrm{~mm}$

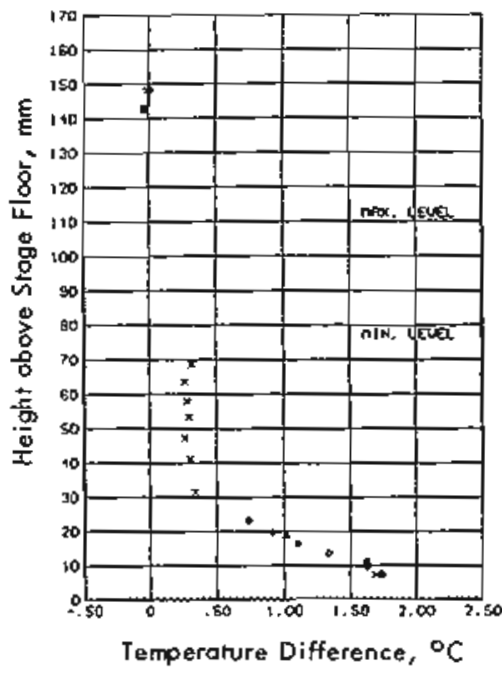

8. Distance from Gote: $400 \mathrm{~mm}$

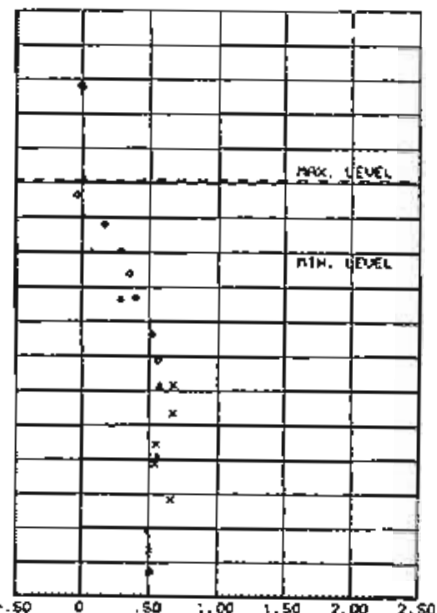

Temperoture Difference, ${ }^{\circ} \mathrm{C}$
C. Distance from Gate: 104

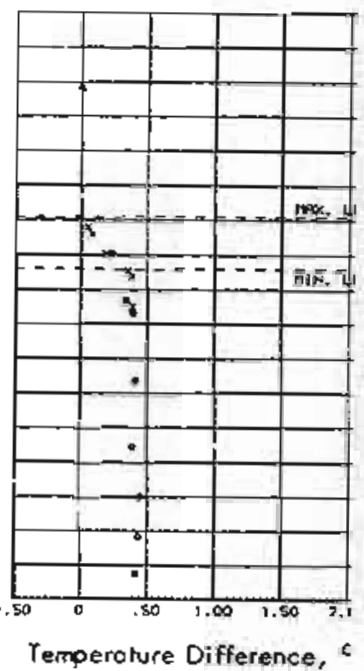

Fig. 5. Typical temperature distribution obtained by the thermistor comb.
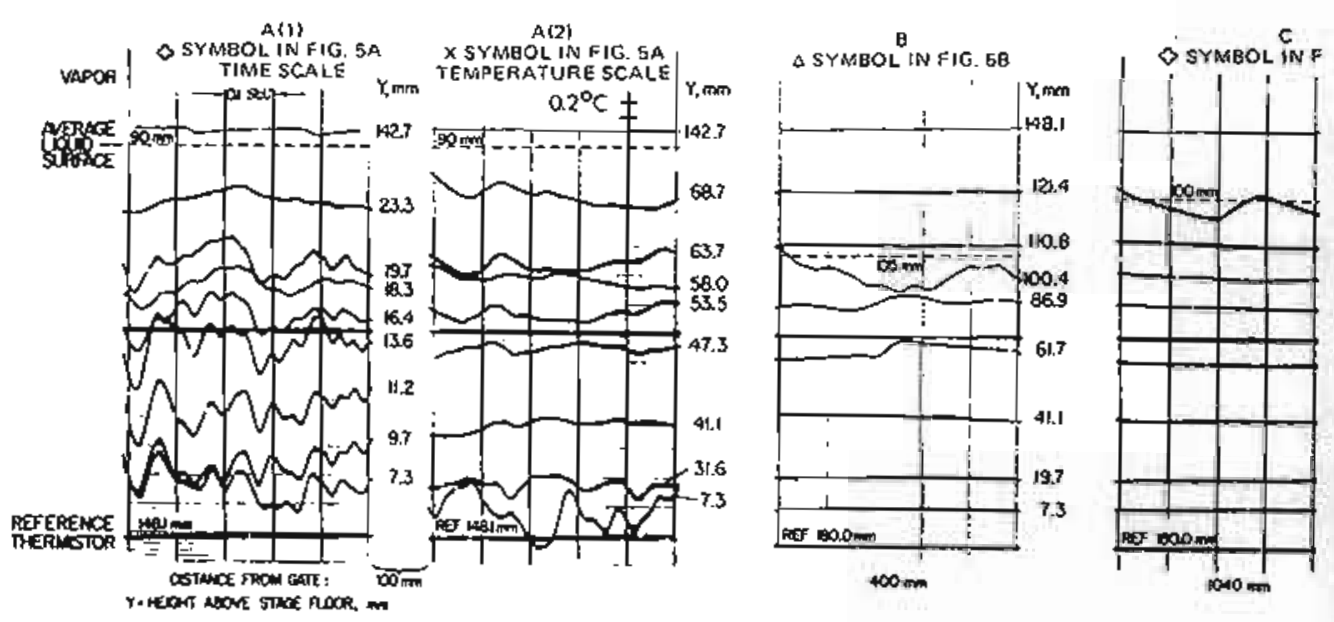

Fig. 6. Actual oscillographic records of the temperature fluctuations, as obt the thermistor comb.

The next regime is one of open channel flow and consists essent the liquid phase only, although some bubbles are carried along fi roller until they are eventually released at the free surface. Long waves, (roughly $0.4 \mathrm{~m}$ wavelength) which seem to originate from th where the expanding jet meets the surface, are apparent in this An increase in the flow rate of the flashing liquid causes an increas 


\section{HORIZONTAL FLASH EVAPORATOR}

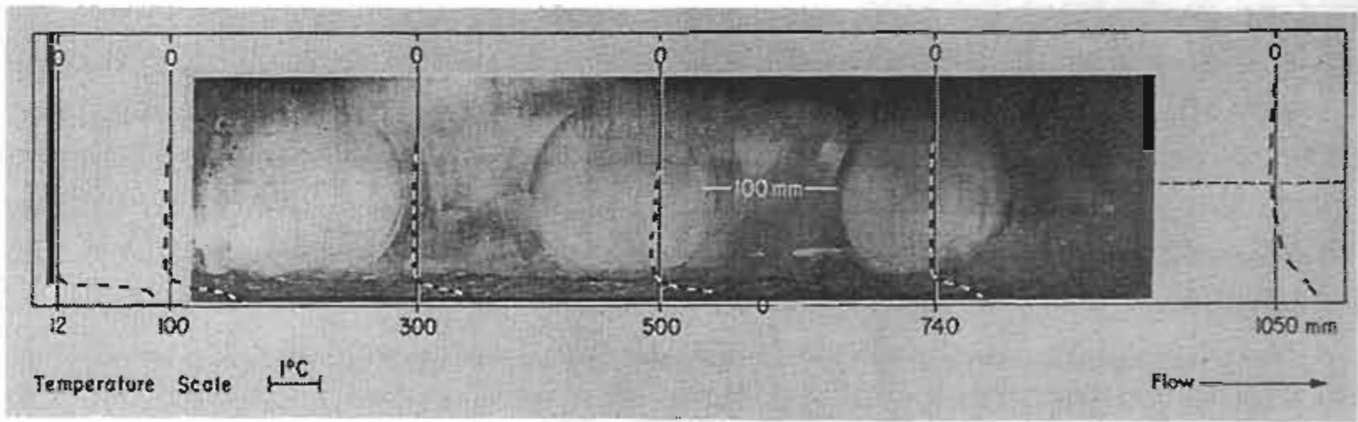

Fig. 7. Temperature distribution in the flash evaporator run No. 22 (Supercri

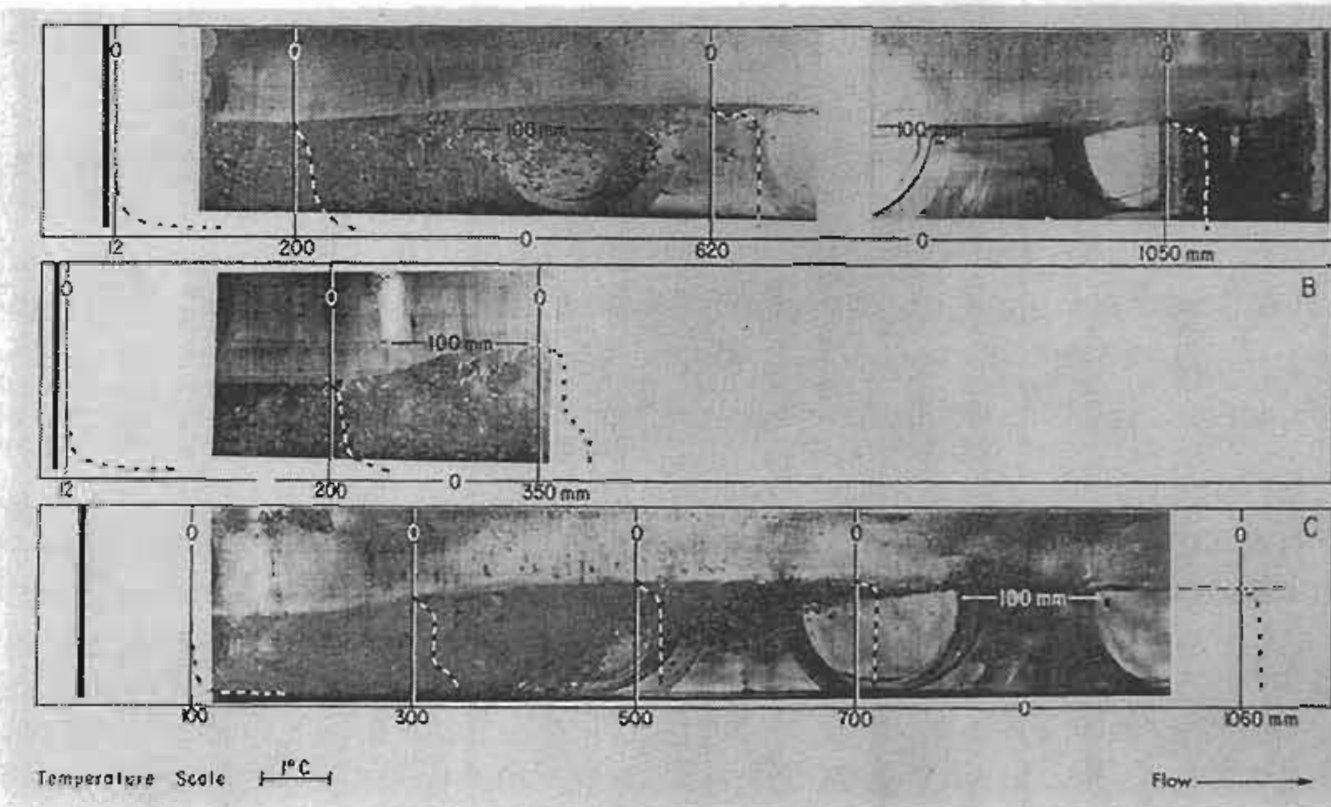

Fig. 8. Temperature distribution in the flash evaporator runs: A: No. 8; B: $\mathrm{A}$ C: No. 11 (foaming brine).

length of the hydraulic jump, $L_{\mathrm{j}}$. The higher liquid velocities also , bubbles further into the open-channel flow region. Increasing the flash $\triangle T_{F C}$ at a constant flow rate slightly decreased the length of the $\mathrm{j}$ : the end of the jump is more abrupt and distinct, and the elevation o upwelling of the free surface at this location is increased. In additic appears that the vapor fraction of the two-phase roller is higher and ext further down into the expanding liquid jet until it reaches the bo of the channel.

\section{Temperature profiles}

A typical temperature distribution in the flash evaporator, obtained ir no. 5 (Fig. 4) is displayed in Fig. 5. Curves faired through such experim: points are overlayed on the photographs of the flashing liquid in $\mathrm{Fi}$ 
7 , and 8 . The latter display shows clearly the temperature profiles at $v$ axial locations, in relation to the actual flow pattem, and enables comparison between the various runs. It can be seen in all cases that emerging under the sluice. gate expands into the colder overlaying two backflow roller, until it meets the free surface. The steepest tempe gradients exist at the interface between the expanding forward-flow $j$ backflow roller. The fluid downstream of the hydraulic jump is esse: at a unifrom temperature, with a large gradient at the free surfact stream has also lost most of its available $\Delta T_{F C}$. Further downstrear evaporative cooling extends deeper into the stream, but the rate of $c$ is much slower.

\section{Temperature and pressure fluctuations}

Some typical temperature fluctuations for run No. 5 (Figs. 4 , shown in Fig. 6. Sections of the oscillographic record of the ther comb temperatures are reproduced for three axial locations ( $x$ me: from the upstream edge of the gate), providing the variation of the perature fluctuations in the flash stage. The number next to each indicates the depth $\mathrm{Y}$ in $\mathrm{mm}$ of the thermistor associated with that The bottom curve was produced by the thermistor that was used as ref, in the differential Wheatstone bridge. The dashed line indicates the $\mathrm{pc}$ of the free surface and is positioned between the thermistors that are to the free surface on both sides. A scale is provided for temperatu. time. All temperature records located on one strip were obtained taneously. Several conclusions may be made on the basis of these result

For the subcritical flow of fresh water (Figs 4 and $8 \mathrm{~A}, \mathrm{~B}$ ), the ter ture fluctuations are intense and of high frequency at $100 \mathrm{~mm}$ from th of the sluice gate, but are rather small in the overlaying roller at tha location. These fluctuations are transported towards the free surfac the expansion of the jet and are also amplified by the mixing action hydraulic jump, with an accompanying decay in the higher freq components. The fluctuations observed at this axial location in the $\mathrm{v}$ of the free surface arise mainly from the wavy action at that surface.

An increase in $\triangle T_{F C}$ causes an increase in the amplitude of the: ations. With an increase in the flow rate, the fluctuations pervade ir ingly larger regions of the stream and their frequency increases.

The highest frequencies of the temperature fluctuations were 10-: No fluctuations were observed in the vapor space other than long (1 minute) waves, probably resulting from the response of the tempe controller.

\section{Flashing of $\mathrm{NaCl}$ solutions}

The most prominent phenomenon distinguishing the flashing of solutions from that of fresh water is creation of substantial and stead? 
as depicted in Fig. $8 \mathrm{C}$ for run no. 11. At the inlet of the flash stage, the fo pervades from the free surface region with increasing $x$. The vapor temp ture isotherm extends much deeper into the liquid than in the case of $f$ i water. This indicates that the foam in the former case is cooled do

The phenomenon of foaming of $\mathrm{NaCl}$ solutions and seawater is a fam one in desalination plants, and anti-foam chemicals are usually added to : press it (to prevent excessive carryover). Foaming usually results from surface-active organic matter in the liquid. The solution used in the pre: experiments was prepared in meticulously cleaned vessels from analyt grade $\mathrm{NaCl}$ dissolved in city water. The flash evaporator system was cl no greases or detergents were used, and it has been in operation for sev months with city water ans was blown-down frequently. An analysi: the solution indicated a content of $0.2 \mathrm{ppm}$ of anionic surfactants. W this analysis does not include all organic matter, it does embrace mos the common surfactants.

It is noteworthy that the foaming action did not increase the carry, of brine into the distillate. As a matter of fact, the salinity of the proc $(3 \mathrm{ppm})$ was lower than that of the product in most runs with flasl city water.

The differences between the flashing of $\mathrm{NaCl}$ solutions and of $\mathrm{f}$ water is not confined to the visual appearance of the foam, but extr to the total process by the influence that the foam has on the fluid dyr ics, evaporation and heat transfer mechanisms. Many of the differences evident from Fig. 8 and Table I and will be discussed further below.

\section{Flashing of supercritical streams}

Four supercritical flow runs were performed for comparison with critical flows, by maintaining the same absolute temperature, flow rate $\Delta P_{v}$, while only decreasing the level of the stream in the flash stage. The lit level was lowered until a hydraulic jump formed at the exit from the $f$ stage, in order to maintain the pump suction flooded and thus pre cavitation in the pump.

It has been observed that a fine mist is sprayed above the free surfac the stream. Since the lowest thermistor in the comb is $7.3 \mathrm{~mm}$ from channel bottom, it was not possible to determine the temperature di butions in the shallower supercritical streams. Some of the informa obtained is included in Table I and Fig. 7, indicating that approach to $\mathrm{e}$ librium was not improved by employing supercritical flows. This is cont to the hypothesis in [15], but because of the small number of supercri runs and the above mentioned measurement difficulty, the results car regarded as being of only a preliminary nature.

\section{On the mode of evaporation}

Based on the discussion in the Introduction, the interstage super available for flashing is by itself insufficient for the usual bubble nuclea 
as encountered in nucleate boiling. However, the existence of bubble: flash stage, particularly in the roller of the hydraulic jump, is a experimental observation. It is generally agreed (cf. [16-18]) the particles in the liquid are unlikely to serve as bubble nuclei. Mo such particles were absent from the flashing liquid due to continu filtering during the experiment. Free or dissolved noncondensable also eliminated as a potential source because the system was pre-d and then continuously dearated in a closed circulation loop during periment. The liquid would therefore have lost such nonconder

Two remaining sources for nucleation are vapor bubble nuclei into the flash stage from the inlet stage, and local pressure reduc the stage inlet due to dynamic action of the streaming liquid, i.e., cavi It is possible that both sources are active in flash evaporators, but present system it seems that cavitation is the more important. If carryover would be of major significance, one could deduce that ve bubbles would form in the flash evaporator if they were eliminated $f r$ incoming stream. In the present system of a nonflashing inlet stag bubbles carried in the stream are created inadvertently. During the op under various conditions of temperature, flashdown and dearation, any bubbles were visible in the inlet stage, yet substantial bubble : always occurred in the flash stage. Further studies would, hower needed to conclusively justify cavitation as the cause for bubble nuc in the flash evaporators.

The existence of the boiling mode is evident from the observat bubbles and their growth. This bubble creation and growth, mainly $\mathrm{cc}$ to the backflow roller and expanding jet, justifies also the rapid temp. drop of the liquid in that region. The surface evaporation mode is present and is particularly prominent in the open channel flow past the hydraulic jump. This is supported by the sharp temperature g observed in the liquid at the free surface in the absence of bubbles, a gradual development of the thermal boundary layer (cooling) at this with increasing axial distance.

\section{On the fluid dynamics of the system}

To compare the hydrodynamics of the present flash evaporator to larger scale systems, Froude number modeling is applied and the o of the gate, $h g$, is chosen as the scale modeling parameter (cf. [1! this case, the following modeling relations are obtained:

$$
\frac{h_{\mathrm{g}_{1}}}{h_{\mathrm{g}_{2}}}=\frac{h_{\mathrm{1}}}{h_{2}}=\frac{L_{\mathrm{g}}}{L_{2}} \text { and } \mathrm{Fr}_{1}=\mathrm{Fr}_{2}
$$

where $h$ is the water level in the stage and $L$ the stage length. 
From the equality of Froude numbers:

$F r_{1}=F r_{2} ;$ i.e. $\frac{V_{B_{1}}}{\left(g h_{1}\right)^{1 / 2}}=\frac{V_{B_{2}}}{\left(g h_{2}\right)^{1 / 2}}$

However,

$V_{B}=\frac{m_{B}}{\rho_{B} b h}$

So that

$m_{B_{2}}=\left(\frac{h_{2}}{h_{1}}\right)^{3 / 2}\left(\frac{b_{2}}{b_{1}}\right) m_{B_{1}}$

A comparison will be made with the $1 \mathrm{ft}$ wide, $11 \mathrm{ft} 3 \mathrm{in}$. long sy used by the American Machine and Foundry Company [2] and to $10 \mathrm{ft} 6 \mathrm{in}$. wide, $11 \mathrm{ft} 4 \mathrm{in}$. long stage of the OSW plant at San Diego The liquid level in both cases was $1 \mathrm{ft}$ to $2 \mathrm{ft}$, and an average of 1.5 used in the calculation. Taking the flow rates in the present experir as $m_{B 1}$ and the upscaled ones as $m_{B 2}$, we get for the AMF system:

$m_{B_{2}}=\left(\frac{1.5}{0.33}\right)^{3 / 2}\left(\frac{12}{3.1}\right) m_{B_{1}}=37.6 m_{B_{1}}=23 \mathrm{~kg} / \mathrm{s}$ to $94 \mathrm{~kg} / \mathrm{s}$

a flow which is somewhat lower here than the $126 \mathrm{~kg} / \mathrm{s}\left(10^{6} \mathrm{lb} / \mathrm{h} \mathrm{ft}\right.$ w in the AMF experiments.

For the OSW system:

$m_{B_{2}}=\left(\frac{1.5}{0.33}\right)^{3 / 2}\left(\frac{126}{3.1}\right) m_{B_{1}}=394 m_{B_{1}}=240 \mathrm{~kg} / \mathrm{s}$ to $986 \mathrm{~kg} / \mathrm{s}$

two to six times higher here than the $75 \mathrm{~kg} / \mathrm{s}$ to $150 \mathrm{~kg} / \mathrm{s}$ used in the $\mathrm{c}$ stage of the OSW evaporator.

It is of interest to compare the observed flows with nonflashing water flows. Of particular importance are the properties of the hyd jump. As observed from the temperature profiles, most of the total perature drop $\Delta T_{F C}$ occurs within the length of this jump, and thus 
exists the possibility that stage performance and equilibrium could be r to the length of this jump. The length of the jump, $L_{i}$, as estimated frc actual flashing flow, is listed in column 16 of Table $\mathrm{I}$. The values in Table I were obtained by taking the highest liquid level (or upw as the end of the jump. All length measurements in the axial $x$ dir are measured from the upstream edge of the gate. It can be seen th length of the jump generally increases with the flow rate and wi flashdown $\triangle T F C$.

To compare the length of the jump in flashing flows to that in cold Stepanov's [20] correlation is used:

$L_{j c}=3.31 /\left[\left(\frac{h-h_{g d}}{h_{c}}\right) \frac{1}{\mathrm{Fr}_{u c}}\right]^{0.885}$

Where $L_{j c}$ is the calculated length of the cold water jump, $h_{g d}$ is the l $\epsilon$ the liquid at the downstream side of the gate (determined experimen $h_{c}$ is the critical depth of the flow $(\mathrm{Fr}=1)$, and $\mathrm{Fr}_{v c}$ is the Froude $\mathrm{nl}$ at the Vena Contracta. This correlation has also been examined by [21] and found to adequately represent the length of the jump. Its 1 for $L_{j c}$ are displayed in column 17 of Table I. It can be seen that alti $L_{j c}$ changes in the same way as $L_{j}$, the actual computed length $L_{j c} \mathrm{i}$ stantially larger: from about $500 \%$ at the lowest flows to about $50 \%$ ] at the highest ones. An immediate explanation for this difference is $r$ to the reduced density of the two phase roller in the flashing case, as pared to that in the cold water case. Another possible influence $c$ length of the jump is the motion of the bubbles.

9. A parametric examination of the total evaporative heat transfer The rate of total evaporative heat transfer is calculated from the mee distillate production rate and is displayed in Fig. 9. It can be seen tha creases with the interstage vapor pressure drop $\triangle P_{v}$ and the flow ra expected. At $80^{\circ} \mathrm{C}$ the heat rate for a given $\triangle P_{u}$ and flow rate is highe: at $100^{\circ} \mathrm{C}$ because the same $\Delta P_{v}$ is associated with a higher temperature $\triangle T_{F C}$ in the $80^{\circ} \mathrm{C}$ case.

\section{Approach to equilibrium}

The approach to equilibrium, $\Delta^{\prime}$, is most commonly defined as:

$\Delta^{\prime}=\bar{T}_{0}-T_{v}$

where $\bar{T}_{0}$ is the average temperature of the liquid at exit from the stage and $T_{u}$ the temperature in the vapor space. Table I shows that creases with increasing $\triangle T_{F C}$ at various flow rates and temperatures 


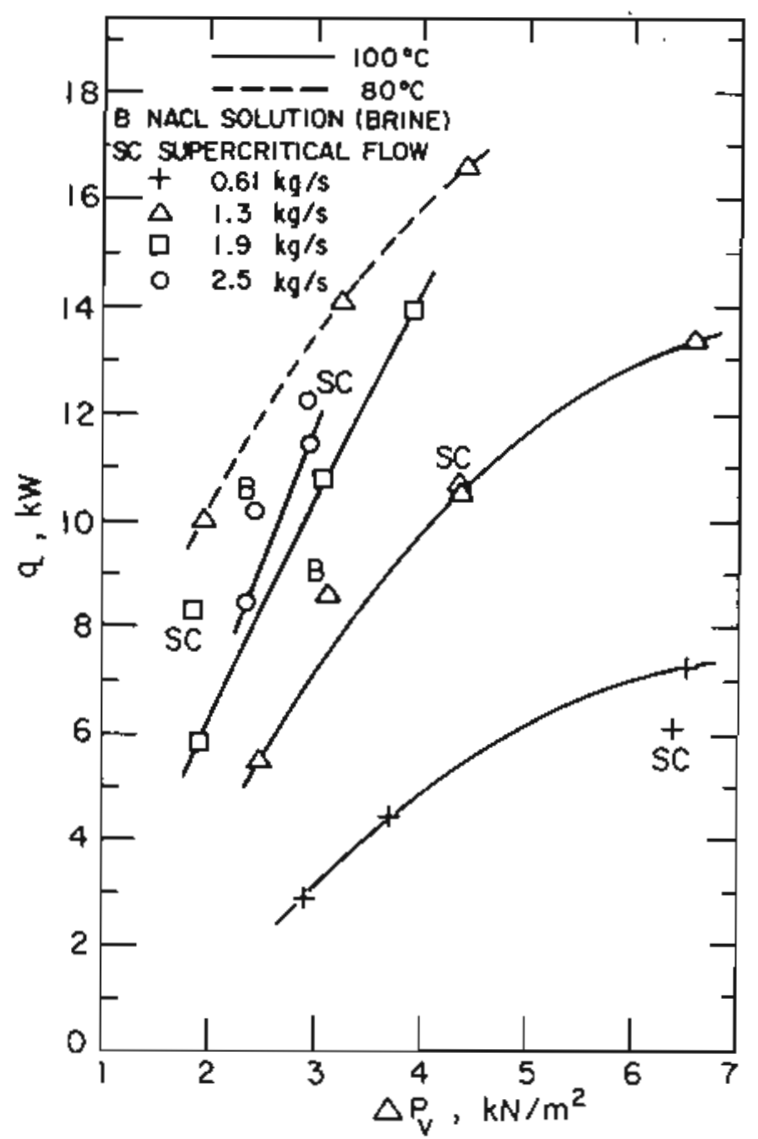

Fig. 9. Total evaporative heat $q$ vs. interstage vapor pressure drop $\Delta P_{y}$ at different rates and absolute temperatures.

trend, as well as the increase of $\Delta^{\prime}$ with decreasing absolute tempera is similar to that shown by the AMF and $\mathrm{BLH}$ correlations of prer experimental data $[22,23]$.

The dependence of $\Delta^{\prime}$ on the flow rate is more complex. This fact can be seen in the disagreement between the above mentioned correlat While AMF correlates $\Delta^{\prime}$ to (flow rate) ) $^{0.455}, \mathrm{BLH}$ correlates it to 1 rate) 0.182 (the exponent is two and a half times smaller), implying a $s$ icantly reduced dependence on the flow rate in the latter case. It is re: able to assume that the approach to equilibrium is improved with incr mixing of the flashing liquid and/or by the creation of larger liquid-i interface areas for a given liquid volume. Both phenomena depend of flow conditions, such as the mixing properties of the jump, and or absence or existence of sprays and foams. The mixing properties 0 : jump are dependent in a complex manner on the flow rate, the Froude 1 ber, and the degree of submergence [24]. 
The values of $\Delta^{\prime}$ were compared with values calculated from the mentioned $\mathrm{AMF}$ and $\mathrm{BLH}$ correlations, and the latter are listed in col and 8 of Table I. The AMF correlation underestimates the present by approximately one order of magnitude and is probably suitabl for flow rates substantially higher than those encountered in our , ments. The BLH correlation is much closer to our results: it gives va $\Delta^{\prime}$ that are usually $1 / 3$ to $1 / 2$ of those corresponding to the fresh experiments but is quite accurate for the salt water flows. This be justifies the reduced dependence of $\Delta^{\prime}$ on the flow rate as assumed by Both correlations, however, leave much to be desired. In addition to t. viously mentioned parameters characterizing the hydraulic jump (s Fr and the degree of submergence), such correlations should also i parameters of stage length and geometry, at least.

A nondimensional number expressing the approach to equili defined here as the "fractional nonequilibrium allowance" $(1-\beta)$ :

$$
1-\beta=\frac{\bar{T}_{0}-T_{u}}{\bar{T}_{n}-T_{v}} .
$$

expresses the ratio between the nonequilibrium allowance $\Delta^{\prime}$ and ths "available" superheat $\left(\bar{T}_{i n}-T_{v}\right)$. The experimental values of ( $1-$ listed in column 9 of Table I and plotted in Fig. 10.

In the case of the flashing brine runs, the nonequilibriun is reduce to three fold as compared to the fresh water runs. This is most probab to the foaming action which always persisted with the brine, and whi absent with fresh water. The foam disperses much of the liquid int films enveloping vapor bubbles and thus increases significantly th available for evaporation, and reduces the heat transfer path length would indeed tend to bring the superheated liquid closer to therma librium with the vapor.

\section{CONCLUSIONS}

1. The major roles of the nucleate boiling mode of evaporation the hydraulic jump in the horizontal flash evaporator were establish the range of parameters in this study.

2. It is postulated that bubble nucleation in the flash evaporator pr comes about due to a cavitation-like phenomenon. Further studies progress to evaluate this postulate.

3. The flashing of $\mathrm{NaCl}$ solutions was accompanied by strong fo mainly in the submerged sluice gate flow region. The foaming acti improved the evaporative heat transfer in the stage and has reduc 


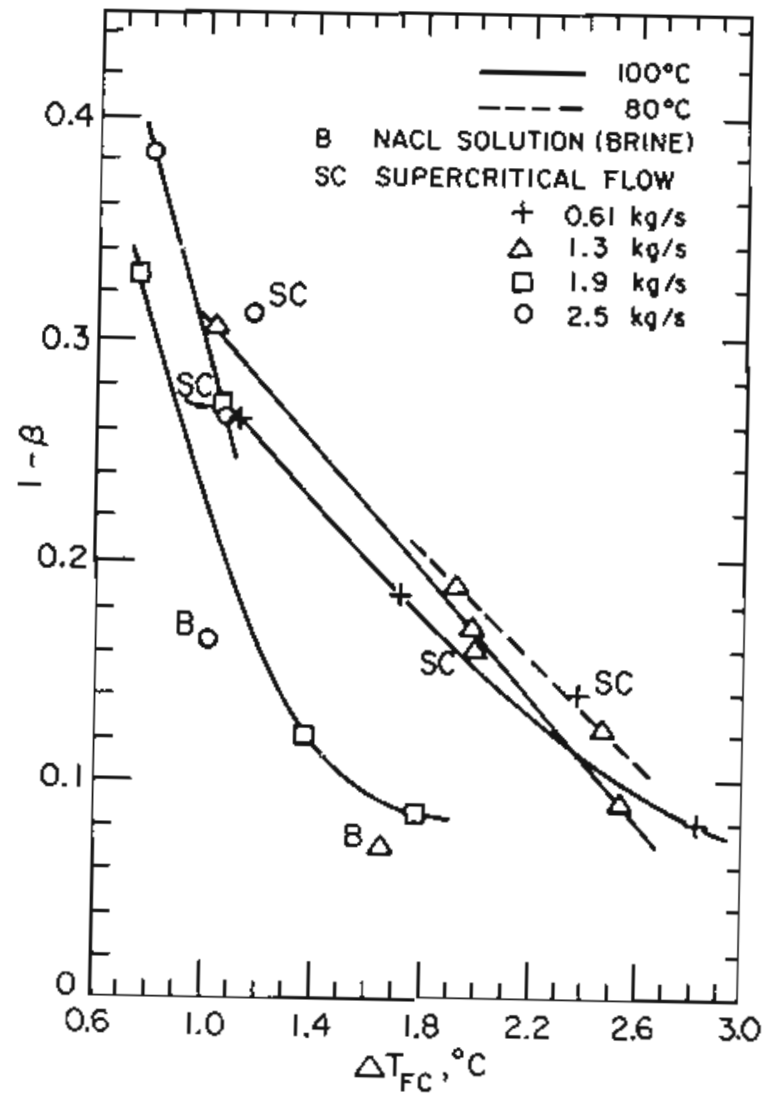

Fig. 10. Fractional nonequilibrium allowance $(1-\beta)$ vs. flashdown $\Delta T_{F C}$ at diff flow rates and absolute temperatures.

nonequilibrium allowance $\Delta^{\prime}$ and the fractional nonequilibrium allow: $(1-\beta)$, by a factor of two to three. The purity of the product remaine least as high ( $3 \mathrm{ppm})$ as that in the case of flashing city water.

4. The flashing liquid temperature approaches closer to the vapor s] temperature when the stage flashdown $\Delta T_{F C}$ is increased. The rela of this approach to the flow rate is more complex. The increase in rate affects the heat transport in at least two ways: it enhances the mi process, and creates more favorable conditions for bubble nucleation growth by decreasing the local pressure in the liquid close to the inters aperture. These effects depend on the flow rate and on the properties 0 : resulting hydraulic jump.

\section{ACKNOWLEDGEMENT}

The authors wish to acknowledge the invaluable assistance to this $s$ extended by Messrs. J.C. Hensley, J. Leibovitz, Marvin M. Mendonca, 
Nishiyama, G.P. Schwab, and P.G. Young, and the support and cour tended by Dr. A.D.K. Laird.

The experimental work was performed at and funded by the $S t$ Conversion Laboratory of the University of Califomia. The subs analysis was partially funded by NSF Grant ENG 75-10525 to t author, at the University of Pennsylvania.

\section{REFERENCES}

1. Richardsons Westgarth and Co., Office of Saline Water, Res. Develop. Prog No. 108,1964

2. F.W. Gilbert, C.H. Coogan and D.A. Fisher, ASME Paper No. 70-FE-39, $197 \mathrm{C}$

3. A.N. Dickson and A.J. Addlesee, Third Intern. Symp. on Fresh Water from Dubrownik, 4 (1970) 31-41.

4. Catalytic Construction Co., Office of Saline Water, Res. Develop. Progr No. 645,668 , and 705,1971 .

5. N. Lior, Ph.D. dissertation in Mechanical Engineering, University of $\mathrm{C} \varepsilon$ Berkeley, 1973.

6. G. Coury, J.C. Deronzies and J. Huyghe, Desalination, 12 (1973) 295-313.

7. S. Stecco, Fourth Intern. Symp. on Fresh Water from the Sea, Heidelberg, $487-495$.

8. N.K. Tokmantsev and V.B. Chernozubov, Fourth Intern. Symp. on Fresh Wa the Sea, Heidelberg, 1 (1973) 497-505.

9. C.H. Coogan, W. Giger Jr., and F.E. Steigert, ASME Paper No. 74-WA/PID-

10. R.D. Veltri, Ph.D. Dissertation in Mechanical Engineering, University of Con 1974 .

11. T. Fujii, et al, Heat Transfer-Japanese Research, 5 (I) (1976) 84-95.

12. S.G. Serag El Din, M.A. Darwish and H.T. El-Dessouki, Ind. Eng. Chem. Pror Dev., 17 (4) (1978) 381-388.

13. N. Lior, J. Leibovitz and A.D.K. Laird, Desalination, 13 (1973) 91-94.

14. N. Lior, J. Leibovitz and A.D.K. Laird, Rev. Sci. Instr, 45 (11) (1974) 1341

15. R.P. Hammond, Chem. Tech., 1 (1971) 754-757.

16. R.T. Knapp, Trans. ASME, 80 (1968) 1315-1324.

17. M.S. Plesset, Cavitation State of Knowledge, ASME, NY (1968) 15-25.

18. J.W. Holl, J. Basic Eng., Trans. ASME, 92 (1970) $681-688$.

19. H.L. Ornstein, Ph.D. Dissertation, School of Engineering, University of Con: 1970.

20. P.M. Stepanov, Gidrotekhnikaj Melioratsiya, 10 (1) (1958) $43-53$.

21. N. Rajaratnam, J. Hydraul. Div, Proc. ASCE, 91, Paper No. 4403, HY 4 $71-96$.

22. W.R. Williamson and J.R. Hefler, Office of Saline Water, Res. Develop. Pro: No. $575,1970$.

23. Baldwin-Lima-Hamilton Corp. (BLH) Office of Saline Water, Res. Develo] Rept. No. 22 (2969).

24. G.N.S. Rao and N. Rajaratnam, J. Hydraul. Div., Proc. ASCE, 89, Paper 34 (1963) 139-162. 